\title{
Correction to: A brief intervention for PTSD versus treatment as usual: Study protocol for a non-inferiority randomized controlled trial
}

Halvor Stavland ${ }^{1,2+}$, Camilla Refvik ${ }^{1,2+}$, Jarle Eid ${ }^{2}$, Rafiq Lockhat ${ }^{3}$ and Åsa Hammar ${ }^{4^{*}}$

Correction to: Trials 22, 737 (2021)

https://doi.org/10.1186/s13063-021-05674-y

Following the publication of the original article [1], we were notified of the following corrections:

1) Under the headline BWRT:

Incorrect: A recent addition to the brief treatment arena for PTSD is Brain Working Recursive Therapy $\left(\mathrm{BWRT}^{\circ}\right)$ [56], a single-session intervention based on an understanding of PTSD as being caused and maintained by maladaptive processing of the traumatic memory, in which the main goal of the therapy is to help the client change these maladaptive patterns in order to alleviate symptoms. The intervention is carried out following a strict protocol with a well-defined procedure, [56] without the patient having to disclose the full details of the traumatic memory.

Correct: A recent addition to the brief treatment arena for PTSD is Brain Working Recursive Therapy (BWRT ${ }^{\circ}$ ) [75], a single-session intervention based on an understanding of PTSD as being caused and maintained by maladaptive processing of the traumatic memory, in which the main goal of the therapy is to help the client

The original article can be found online at https://doi.org/10.1186/s13063021-05674-y.

* Correspondence: aasa.hammar@uib.no

+Halvor Stavland and Camilla Refvik contributed equally to this work. ${ }^{4}$ Department of Biological and Medical Psychology and Division of Psychiatry, Haukeland University Hospital, University of Bergen, Bergen, Norway

Full list of author information is available at the end of the article change these maladaptive patterns in order to alleviate symptoms. The intervention is carried out following a strict protocol with a well-defined procedure, originally developed by Terence Watts, [56] without the patient having to disclose the full details of the traumatic memory.

2) In the section of authors contribution:

Incorrect: RL has been clinical advisor and is responsible for the development of the original BWRT intervention protocol.

Correct: RL has been clinical advisor and is responsible for the development of the South African adaption of the original BWRT protocol.

\section{Author details}

${ }^{1}$ Faculty of Psychology, University of Bergen, Bergen, Norway. ${ }^{2}$ Center for Crisis Psychology, University of Bergen, Bergen, Norway. ${ }^{3}$ Cape Town, Summit Clinic, Cape Town, South Africa. ${ }^{4}$ Department of Biological and Medical Psychology and Division of Psychiatry, Haukeland University Hospital, University of Bergen, Bergen, Norway.

Published online: 16 December 2021

\section{Reference}

1. Stavland, et al. A brief intervention for PTSD versus treatment as usual: Study protocol for a non-inferiority randomized controlled trial. Trials. 2021; 22:737. https://doi.org/10.1186/s13063-021-05674-y.

C C The Author(s). 2021 Open Access This article is licensed under a Creative Commons Attribution 4.0 International License, which permits use, sharing, adaptation, distribution and reproduction in any medium or format, as long as you give appropriate credit to the original author(s) and the source, provide a link to the Creative Commons licence, and indicate if changes were made. The images or other third party material in this article are included in the article's Creative Commons licence, unless indicated otherwise in a credit line to the material. If material is not included in the article's Creative Commons licence and your intended use is not permitted by statutory regulation or exceeds the permitted use, you will need to obtain permission directly from the copyright holder. To view a copy of this licence, visit http://creativecommons.org/licenses/by/4.0/ The Creative Commons Public Domain Dedication waiver (http://creativecommons.org/publicdomain/zero/1.0/) applies to the data made available in this article, unless otherwise stated in a credit line to the data. 